\title{
Growth Pattern Among Yemeni Children Suffering from B Thalassemia Major in Relation to Serum Ferritin the Yemeni Society for Thalassemia and Genetic Blood Disorder - Sana'a Yemen
}

\author{
Dr. Abdullah A. K. Al-Tayar ${ }^{{ }^{*}}$ and Dr. Ali Ahmed Mohammed Al-Zaazaai ${ }^{2 *}$ \\ ${ }^{1}$ Consultant Pediatric, Pediatric department Algomhori hospital in Sana'a Yemen \\ ${ }^{2}$ Clinical Pharmacy of Wenzhou Medical University, Zhejiang Province, China
}

\begin{abstract}
Received: October 11,2019; Accepted: October 28,2019; Published: November 14,2019
*Corresponding author : Dr. Abdullah A. K. Al-Tayar. PhD, consultant Pediatric, Pediatric department Algomhori hospital in Sana'a Yemen. Tel: 00967777708692; E-Mail: Abdallah_altyar@yahoo.com and Dr. Ali Ahmed Mohamed Al-Zaazaai. M.Sc. in Clinical Pharmacy of Wenzhou Medical University, Zhejiang Province, China. Tel: 00967- 771207965; E-mail: Alzaazaiali@yahoo.com
\end{abstract}

\begin{abstract}
Background: Thalassemia are a heterogeneous collection of genetic disorders categorized by decreased or absent production of one or more globin chains that make up a hemoglobin molecule.

Objective: The main aim of the present study was to evaluate the growth pattern and growth failure rate in children with hyper transfused $\beta$ thalassemia major those on chelating therapy in comparison with serum ferritin level in the Yemeni society for thalassemia and genetic blood
\end{abstract} disorder.

Methods: In this comparative descriptive study, the growth parameters (height, weight) and serum ferritin of 109 patients aged 2-18 years (52 males 47 females) with $\beta$-thalassemia major in The Yemeni society for thalassemia and genetic blood disorder - Sana`a, were taken, In which the growth was compared with normal growth charts for the same age and gender according to WHO then the growth pattern is camper with serum ferritin and degree of hemosiderosis.

Results: Growth retardation below 5 centiles were found in (67.889\%) of total surveyed Patients for both height and weight in both gender, in details there are $(71.60 \%)$ are short and under 5 th centile in compare with height of normal children at same age and gender (38.46\% is female patients and $61.53 \%$ is male patients) and there are (67.9\%) are underweight and under 5th centile in compare with weight of normal children at same age and gender ( $37.83 \%$ is female patient and $62.16 \%$ is male patients).

Conclusion: Growth failure (underweight and short stature) significantly occurs in thalassemia patients compared to normal children of the same age and sex, and such growth retardation was more in Yemeni patients compared with same studies on other countries than Yemen.

Keywords: Thalassemia; Genetic blood disorder; Yemeni patients.

\section{Introduction}

Inherited blood disorder considers as big health problem that we couldn't be omitted because of the chronic course of disease with severe clinical picture and complication that may lead to death or even sever disfiguration include growth restriction causing deep social and sociological harm in the affected individual. Regarding hemoglobin disorder epidemiology there is at least $5.2 \%$ (and over 7\% of pregnant females) in the world carry a significant difference in of hemoglobin disorders[1].

Hemoglobin S accounts for $40 \%$ of carriers but causes over $80 \%$ of disorders because of localized very high carrier prevalence: around $85 \%$ of sickle-cell disorders and over $70 \%$ of all affected births occur in Africa. In addition, at least $20 \%$ of the world population carries a+ thalassemia. Around $1.1 \%$ of couples worldwide are at risk for having children with a hemoglobin disorder and 2.7 per 1000 conceptions are affected, affected birth prevalence is assessed at 2.55 per 1000 . Most affected children born in high-income countries survive with a chronic disorder, while most born in low-income countries die before the age of 5 years. Hemoglobin disorders donate the equivalent of $3.4 \%$ of mortality in children aged under 5 years worldwide or $6.4 \%$ in Africa. Annually there are About 56000 have a major thalassemia, including at least 30000 who need regular transfusions to stay alive and 5500 who die perinatal caused by a thalassemia main[1,2].

Each year there are 1.33 million at-risk pregnancies. In principle, all need the agreement of prenatal diagnosis. about 
$12 \%$ of children born with transfusion-dependent $\beta$ thalassemia are actually transfused, and less than $40 \%$ of those transfused obtain suitable iron-chelation therapy. About 100000 patients are currently living with regular transfusions, and at least 3000 die once a year in their teens or early 20 s from uncontrolled iron overload[1].

In Yemen, hemosiderosis is the main cause of growth retardation, this study is aimed to assess the growth pattern and growth failure rate in Yemeni children with $\beta$ thalassemia major which tend to be exaggerated especially among the poor who unfortunately make the majority of patients. and among the obvious deteriorated in health services in general and prolonged instability in my country due to war with the absence of essential drugs like chelating drugs this problem appears obviously causing major tragedy among my patients. Growth is a dominant biological activity during the first two years or so of human life, including, of course, nine months of prenatal life.

Growth is an increase in the size of the body as a whole or the size attained by specific parts of the body. It is an important distinguishing of all living organisms. The term development is repeatedly used along with growth and even measured synonymous by some people.

Growth means the increase in the size of the various parts and organs of the body by multiplication of cells and intercellular mechanisms during the period commencing from fertilization to physical maturity. Changes in size are results of three underlying cellular processes: (a) an increase in cell number or hyperplasia; (b) an increase in cell size or hypertrophy; (c) an increase in intercellular substances or accretion. The increase in number is a function of cell division (mitosis), which involves the replication of DNA and the subsequent migration of the replicated chromosomes into functional and identical cells. The increase in cell size involves an increase in functional units within the cell, mainly protein and substrates, as is especially evident in the muscular hypertrophy that occurs with regular resistance exercise.

According to Watson and Lowery " growth means an increase in the physical size of the whole or any of its parts." It can be measured in terms of centimeters and kilograms or metabolic balance i. e. retention of hydrogen and calcium in the body. Juan Comas defines it " as the objective manifestation of hypertrophy and hyperplasia of the organism constituent tissues and is determined by postnatal body size[3]."

Progress refers to the increase of functional capacity in perfect form resulting from the production of specialized tissues from unspecialized ones. The term progress has been variously defined by scientists. Comas (1960) regards progress as a quality peculiar to living matter that carries it through the process of progressive evolution to a state of perfect function. Hurlock (1941) considers progress as changes in its progressive series which are orderly and coherent and which lead to maturity. It is, in fact, the consequence of cellular differentiation that the character and its specificity result into perfect function[3].

Maturation often described as the process of becoming mature, or progress toward the mature state.

Maturity, however, varies with the biological system measured. Sexual maturity is fully functional reproductive capability [3].

\section{Factors Affecting Growth}

The integrated nature of growth and maturation is largely maintained by a constant interaction of genes, hormones, nutrients and other factors. These factors also influence physical performance. Some are hereditary in origin. Others, such as season, dietary restriction, severe psychological stress, originate in the environment and simply affect the rate of growth at the time they are acting. Others again, such as socio-economic class, reflect a complicated mixture of hereditary and environmental influences and probably act throughout the whole period of growth [3].

\section{Thalassemia}

The term "thalassemia" refers to a group of blood diseases characterized by decreased or absent synthesis of normal globin chains. According to the chain whose synthesis is impaired, the thalassemia are called $\alpha-, \beta-, \gamma^{-}, \delta-, \delta \beta-$, or $\varepsilon \gamma \delta \beta$ thalassemia. Most thalassemia are inherited as recessive traits [4]. Thalassemia occurs in approximately 4.4 of every 10,000 live births. $\alpha$-thalassemia is most common in individuals of African and Southeast Asian descent, while $\beta$-thalassemia is most common in individuals of Mediterranean, African, and Southeast Asian descent . About $5 \%$ of the world's population has a globin variant, but only $1.7 \%$ has $\alpha$ - or $\beta$-thalassemia trait. Thalassemia trait affects $5-30 \%$ of people in these ethnic groups[2].

\section{Endocrinopathy \& growth retardation in thalassemia}

The most common endocrine irregularities in patients with thalassemia include hypo-gonadotropic hypogonadism, growth hormone deficiency, and diabetes mellitus.

Hypothyroidism, hyperparathyroidism and low levels of adrenal androgen secretion with normal glucocorticoid reserve have been described[5]. Normalratesofprepubertal linear growth is detected in patients with regular transfusion programs, but poor pubertal growth and impaired sexual maturation have been observed in well- transfused patients[6,7]. Pituitary dysfunction causes hypogonadotropic hypogonadism, which usually causes abnormal sexual maturation in them. Primary gonadal failure has also been reported occasionally. Growth failure causes by growth hormone (GH) deficiency (hypothalamic and/or pituitary) and hypothyroidism. Delayed sexual maturation and bone disorders cause by DFO toxicity[8,9]. Growth retardation may improve with the administration of exogenous growth hormone. Hypo secretion of adrenal androgen, delay in pubertal development, zinc deficiency, and free- hemoglobin-induced inhibition of cartilage growth have also been implicated in the impairment of growth in patients with thalassemia major[5]. The use of iron-chelating 
drugs has been shown to delay the development of iron-induced damage of cardiac and liver tissue, resulting in improved survival, but the prevention of endocrine damage is less clear. Deferoxamine (DFO) is a siderophore (an iron-binding compound) produced by the bacterium Streptomyces pilosus. It is not absorbed orally and is rapidly cleared; consequently, subcutaneous or intravenous administration is necessary[11]. Iron chelating therapy should be started before clinically significant iron accumulation when patients have received between 10 and 20 red-cell transfusions. Early initiation of DFO, before the age of 10 years, assures normal puberty in the majority of patients[12]. However, the initiation of DFO at a young age could be associated with bone toxicity, which could decrease growth[13].

The main causes of growth retardation in thalassemia patients are

- Growth failure causes by growth hormone (GH) deficiency (hypothalamic and/or pituitary) due to iron overload.

- Growth failure causes by hypothyroidism also as a complication of iron overload.

- complication of using chelating agent before the third year of life ( deferral )

- other causes like genetic, environmental and nutritional.

\section{Iron Overload and Iron Chelation}

\section{Background on Iron Overload, Assessment of Iron Overload, and Iron Chelation}

Red cell transfusion is the mainstay of treatment for thalassemia major; however, over time this therapy results in significant iron overload. Once the body's ability to store iron is exceeded, free iron accumulates and participates in the formation of reactive hydroxyl radicals, which cause denaturation of proteins and membrane damage. Iron overload, iron overload is the major cause of morbidity and mortality in transfused thalassemia patients. If untreated, it is fatal in the first or second decade of life $[14,15]$. Chelation therapy should be started in patients with ferritin over $1000 \mathrm{ug} / \mathrm{l}$; however, once chelation has been initiated, the ferritin should be maintained between $1000-$ $1500 \mathrm{ug} / \mathrm{l}[16,17]$.

\section{Definitions}

Hyper transfusion regimen; lifelong regular blood transfusions, usually administered to maintain the pre-transfusion hemoglobin level above (11-12 g/dl) to ensure near-normal physical activity and growth [18].

\section{Aims and objectives}

The study was conducted with the following aims and objectives: To assess the growth retardation in Yemeni hyper- transfused $\beta$-thalassemia major patients whose on chelating thereby and its relation with serum ferritin in the Yemeni society for thalassemia and genetic blood disorder.

\section{Specific objectives}

- To identify growth patterns in hyper- transfused $\beta$-thalassemia major patients whose on chelating thereby according to height and weight.

- To identify the age group of apparent growth restriction.

- To identify patient serum ferritin and degree of hemosiderosis among hyper transfused $\beta$ - thalassemia major patient.

- To identify the relation of serum ferritin and growth restriction among patients.

\section{Method \& materials}

\section{Study design}

A Cross-sectional descriptive study.

\section{Study population}

The Yemeni society for Thalassemia And genetic Blood disorders - Sana`a, it is the only society for genetic blood disorder in Sana'a and it received more than 2531 patients.

\section{Inclusion Criteria}

The study involves all hyper transfused $\beta$ thalassemia major patients in the society those requested and received in the society at the time of study and come with inclusion criteria.

\section{Exclusion criteria}

Hyper-transfused $\beta$ thalassemia major patients. The age group of 2-18 years. On chelating therapy or need chelating thereby. Serum ferritin more than $1000 \mu \mathrm{g} / \mathrm{L}$

\section{Sample size}

Other types of genetic blood disorders like SCA or other types of thalassemia. All $\beta$-thalassemia patients did not come with a selected age group. All $\beta$-thalassemia patients not on chronic blood transfusion. All $\beta$-thalassemia patients on chronic blood transfusion with ferritin level was less than $1000 \mu \mathrm{g} / \mathrm{L}$.

\section{Selection of cases}

All hyper transfused $\beta$-thalassemia patients those come with inclusion criteria at the time of study who were 109 patients.

\section{Data collection technique}

There is no technique for case selection and all hyper transfused $\beta$-thalassemia patients whose admit in the society at study time and followed the study criteria will be involved.

\section{Study period}

from $1 / 1 / 2018$ to $30 / 1 / 2019$.

\section{Data analysis}

After designing the master - Sheets, all variables were introduced into the computer. The 21st version of statistical 
package for social sciences (SPSS) was used for data analysis Every patient body weight and height with age were compared with the Who growth charts.

\section{Study ethics}

Approval consent from each patient and their parent is taken and, All personal information was hidden and taking into account their privacy.

\section{Figures and tables}

\section{Height on centile}

The study showed that seventy-eight (71.60\%) of total study child is short and under 5th centile in compare with length of normal children at same age and gender, while nine children is on 5th centile and six (6.6\%) on 10th centile and six (5.5\%) are under 25 th centile and seven $(6.4 \%)$ on 25 th centile and one $(0.9 \%)$ on 50 th centile and two $(1.8 \%)$ on 75 th centile.

Among all under 5th centile patient, there are thirteen (63.9\%) female child and forty-eight (77.4\%) male child while among children on 5 th centile there are six (12.8\%) female and three $(4.8 \%)$ male, and among children on 10 th centile there are two ( $4.2 \%$ ) females and four (6.5\%) males, and there are three ( $6.4 \%$ ) female and three ( $4.8 \%$ ) male under 25 th centile and four $(8.5 \%)$ females and three ( $4.8 \%)$ males on 25 th centile, and only one $(2.1 \%)$ female on 50 th centile, and one ( $2.1 \%)$ female and one $(1.7 \%)$ male on 75 th centile. Figure 1

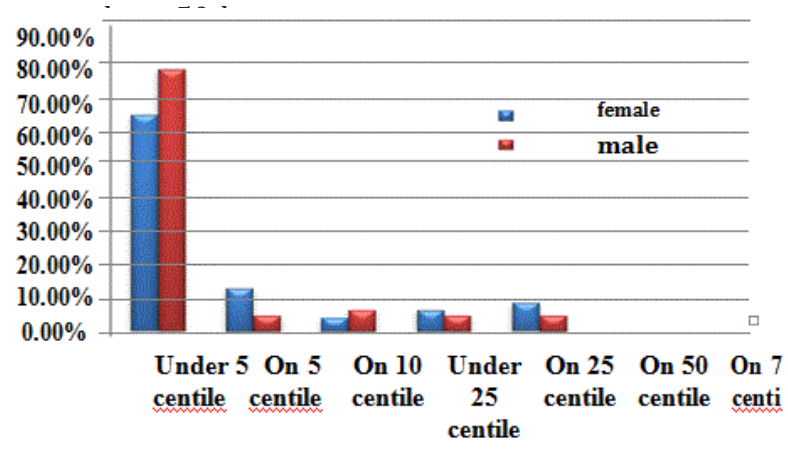

Figure 1: Total distribution of study sample according to height regarding gender

\section{Weight on centile}

The study showed that seventy-four (67.9\%) of total study children are short and under 5 th centile in compare with the weight of normal children at same age and sex, while eleven $(10.1 \%)$ child are on 5 th centile and nine $(8.3 \%)$ on 10 th centile and twelve $(11.1 \%)$ on 25 th centile and three $(2.8 \%)$ on 50 th centile

\section{weight on centile for sex}

Sex differentiation among all under 5th centile
Patient, there are a twenty-eight female child and forty-six male child while among children on 5th centile there are six female and five male, and among children, on 10th centile, there are five females and four males, and six females and six males on 25 th centile, and two female and one male on 50th centile. Figure 2

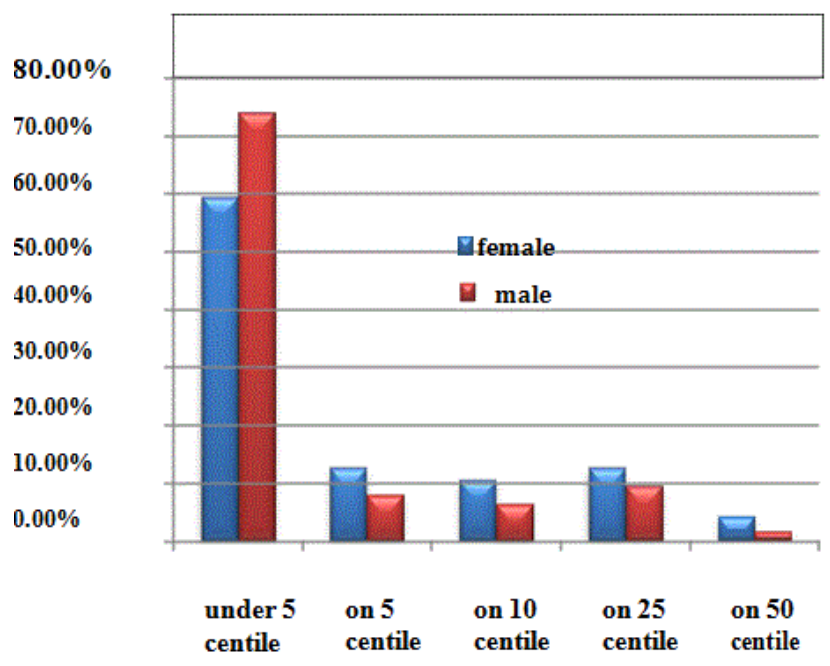

Figure 2: Distribution according to weight regarding gender.

\section{Hemosiderosis among study sample}

The study showed eighty-seven ( $79.5 \%$ ) of children suffer from severe hemosiderosis however twenty $(18,4 \%)$ of children have moderate hemosiderosis and only two (1.8\%) child with mild hemosiderosis. Figure 3

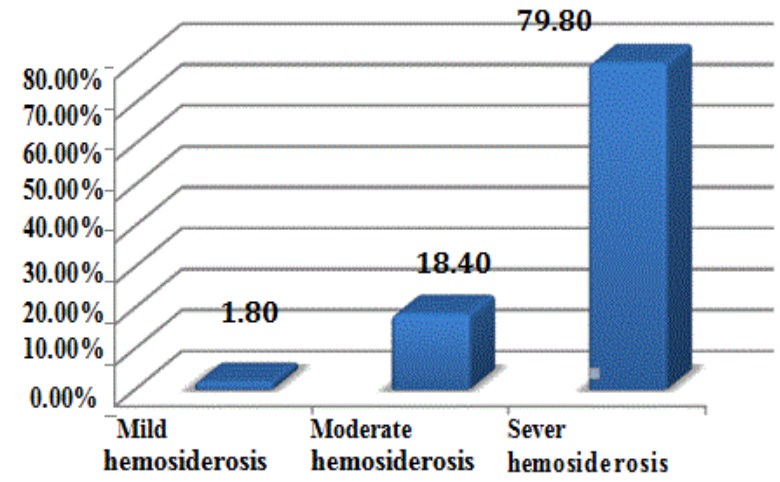

Figure 3: Hemosiderosis among study patients. 


\section{Growth retardation with serum ferritin}

Mean serum ferritin in patients with height and weight more than 5th centile was 4239 and with height and weight of fewer than 5 th centile were 5867.

\section{Mean serum ferritin}

Mean serum ferritin at patients more than 5 th centile was $4976 \mu \mathrm{g} / \mathrm{L}$ and mean serum ferritin at patient more than 5 th centile was $2648 \mu \mathrm{g} / \mathrm{L}$.

\section{Growth Retardation for Age Group}

The study showed that there are seventy-four (67.889\% ) of total surveyed Patients who are below 5 th centile for both length and weight in both sexes. The majority of them beyond the age group of 8 - 18 years forty-seven (63.5\%), while twenty-seven $(36.5 \%)$ beyond the age group of 2-7 years. Figure 4

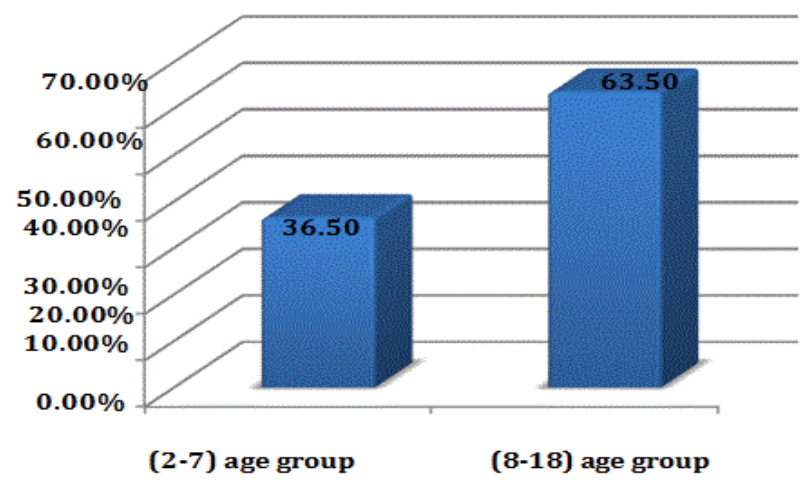

Figure 4: Hemosiderosis among study patients.

\section{Discussion}

This study explores the growth pattern in hyper transfused $\beta$ - thalassemia major patient and its relation with serum ferritin using a cross-sectional method.

\section{Evaluation of the growth pattern among $\beta$ thalassemia major patients}

According to study results the majority of the study patients seventy-four ( $67.889 \%$ ) of total surveyed Patients are below 5th centile for both length and weight in both sex and in detail there are seventy-eight $(71.60 \%)$ of total study children are short and under 5th centile in compare with length of normal children at same age and sex ( $38.46 \%$ is female patients and $61.53 \%$ is male patients ) and seventy-four (67.9\%) of total study children are short and under 5th centile in compare with weight of normal children at same age and sex ( $37.83 \%$ is female patient and $62.16 \%$ is male patients). This percentage is, unfortunately, is higher than the percent showed by study in Jordon prepared by Faiez N. Hattab, with name *Patterns of physical growth and dental development in Jordanian children and adolescents with thalassemia major[19] show that there are $41.9 \%$ (13/31) of total surveyed thalassemia patients are under the 5 percentile in both age and sex. There is study in Iran publish with name *The Study of Growth in Thalassemia Patients and its Correlation with Serum Ferritin Level* by Hashemi A MD, Ghilian R MD, Golestan M MD, Akhavan Ghalibaf M MD, Zare Z MD, Dehghani MA Msc[20], show that $(65.71 \%)$ of thalassemia patients had height less than five percentile which also is less than the result of the total height of Yemeni thalassemia patients. While in study in Egypt named ${ }^{*}$ Growth pattern in children with beta-thalassemia major and its relation with serum ferritin, IGF1 and IGFBP3* by Mona Ramadan Nasr, Nermin Ali Ebrahim, Manal Sayed Ramadan, Omnia Salahedin show a total of $57.6 \%$ of BTM group had retarded linear growth which is also less than our result[21], but one study done in India is the closest result to us this study is * Growth retardation and nutrition in children with thalassemia major* by Vasundhara Kumari, SK Upadhyay, Vineeta Gupta, K Satya Piplani, BD Bhatia show $72.9 \%$ of children below 5 percentile for height and $60.8 \%$ below 5 percentile for weight[22].

\section{Evaluation of the relation of age and growth retardation}

The most obvious age of growth retardation is after the age of 8 years in which the study show that the age group of 8-18 years is the most ages affected by growth retardation with $(63.5 \%)$ of total growth-retarded patient This result agrees with another study in India named *Growth Retardation in Thalassemia Major Patients* by Anita Saxena that show Growth faltering sets in at a much younger age and becomes apparent by 8 years of age[23].

\section{Assessment of the relation of serum ferritin and growth retardation in $\beta$ thalassemia patients}

In assessing the relation of growth retardation with serum ferritin the study show ( 79.5\%) of children suffer from severe hemosiderosis however twenty $(18,4 \%)$ of children have moderate hemosiderosis and only two (1.8\%) child with mild hemosiderosis and the mean serum ferritin at patients more than 5th centile was $4976 \mu \mathrm{g} / \mathrm{L}$ and mean serum ferritin in patient more than 5 th centile was $2648 \mu \mathrm{g} / \mathrm{L}$. while the Irish study*The Study of Growth in Thalassemia Patients and its Correlation with Serum Ferritin Level* by Hashemi A MD, Ghilian R MD, Golestan M MD, Akhavan Ghalibaf M MD, Zare Z MD, Dehghani MA Msc, show the mean serum ferritin at patients with height and weight more than 5 percentile was $2252+/-1040$ and with height and weight less than 5 percentile was $2962+/-1606$. actually this supports the fact that patients with high serum ferritin during childhood have more risk to develop growth retardation but our patients shown much more serum ferritin in the camper with patients in the previous study[24].

\section{Conclusion}

The study reveals that the majority of Yemeni $\beta$-thalassemia major patients are short and under nutrition in comparing with other healthy children or even in comparison with the thalassemia patient in another country, despite regular 
transfusions and chelation therapy. Growth faltering sets in at a much younger age and becomes apparent with older age. On the other side, the study showed the majority of the hyper transfused patient are suffers from severe hemosiderosis in which almost all of them are growth retarded. Poor socioeconomic background compounds and exaggerates the problem. It's clearly that there is a lack of optimal care involving early diagnosis, proper and careful use of transfusion therapy, excellent care and treatment for hemosiderosis and chelating therapy, early detecting of growth retardation and manage.

\section{Recommendation}

The study recommends the following

- Give the optimal care for thalassemia patients in order to prevent hemosiderosis.

- The chelating drug should be available and acceptable at any time and for every patient.

- Take care and treat cases of growth retardation in a thalassemia patient involving early diagnosis and treatment.

\section{Acknowledgment}

All authors great thanks to supervisor Prof. Dr. Xiao Jian in Department of Clinical Pharmacology, School of Pharmaceutical sciences, Wenzhou Medical College, Wenzhou Zhejiang Province, PR. China. Who learn me how to arrange and publish papers in international journal. Thank for China.

\section{Statement of Ethics}

The authors have no ethical conflicts to disclose.

\section{Disclosure statements}

The authors have no conflicts of interest to declare.

\section{References}

1. Bernadette Modell and Matthew Darlison. Global epidemiology of haemoglobin disorders and derived service indicators. Bulletin of the World Health Organization 2008;86(6):480-487.

2. Dean $\mathrm{T}$ Jamison, Joel G Breman, Anthony R Measham, George Alleyne, Mariam Claeson, David B Evans, et al. Disease Control Priorities in Developing Countries. 2nd New York:Oxford University Press;2006

3. Dr. Kaushik Bose. Concept of Human Physical Growth and Development. Vidyasagar University.India

4. Cappellini MD, Cohen A, Porter J, Taher A, Viprakasit V. Guidelines for the management of transfusion dependent thalassaemia (TDT). 3rd Edition. Thalassaemia International Federation. Cyprus.

5. Olivieri NF and Brittenham GM. Iron-chelating therapy and the treatment of thalassemia. Blood. 1997;89(3):739-761. Addendum. Erratum in: Blood. 1997;89(7):2621

6. Sklar CA, Lew LQ Yoon DJ, David R. Adrenal function in thalassemia major following long-term treatment with multiple transfusions and chelation therapy. Evidence for dissociation of cortisol and adrenal androgen secretion. Am J Dis Child. 1987;141(3):327-330.

7. Roth C, Pekrun A, Bartz M, Jarry H, Eber S, Lakomek M, et al. Short stature and failure of pubertal development in thalassaemia major: evidence for hypothalamic neurosecretory dysfunction of growth hormone secretion and defective pituitary gonadotropin secretion. Eur J Pediatr. 1997;156(10):777-783.

8. Oerter KE, Kamp GA, Munson PJ, Nienhuis AW, Cassorla FG, Manasco PK. Multiple hormone deficiencies in children with hemochromatosis. J Clin Endocrinol Metab.1993;76(2):357-361.

9. Low LC, Kwan EY, Lim YJ, Lee AC, Tam CF, Lam KS. Growth hormone treatment of short Chinese children with beta-thalassaemia major without GH deficiency. Clin Endocrinol (Oxf). 1995;42(4):359-363.

10. De Domenico I, Ward DM, Kaplan J. Specific iron chelators determine the route of ferritin degradation. Blood. 2009;114(20):45464551. doi: 10.1182/blood-2009-05-224188.

11. Bronspiegel-Weintrob N, Olivieri NF, Tyler B, Andrews DF, Freedman MH, Holland FJ. Effect of age at the start of iron chelation therapy on gonadal function in beta- thalassemia major. N Engl J Med. 1990;323(11):713-719.

12. De Sanctis V, Katz M, Vullo C, Bagni B, Ughi M, Wonke B. Effect of different treatment regimes on linear growth and final height in betathalassaemia major. Clin Endocrinol (Oxf). 1994;40(6):791-798.

13. Brittenham GM, Griffith PM, Nienhuis AW, McLaren CE, Young NS, Tucker EE, et al. Efficacy of Deferoxamine in preventing complications of iron overload in patients with thalassemia major. $\mathrm{N}$ Engl J Med. 1994;331(9):567-573.

14. Olivieri NF, Nathan DG, MacMillan JH, Wayne AS, Liu PP, McGee A, et al. Survival in medically treated patients with homozygous betathalassemia. N Engl J Med. 1994;331(9):574-578.

15. Porter JB and Davis BA. Monitoring chelation therapy to achieve optimal outcome in the treatment of thalassaemia. Best Pract Res Clin Hematol. 2002;15(2):329-368.

16. Maria-Domenica Cappellini, Alan Cohen, Androulla Eleftheriou, Antonio Piga, John Porter, and Ali Taher. Guidelines for the Clinical Management of Thalassaemia. 2nd Revised edition. Thalassaemia international federation;2008.

17. Anne Yardumian, Paul Telfer, Phil Darbyshire. Standards for the clinical care of children and adults with thalassemia in the UK . 2nd edition. London. UnitKingdom Thalassemia Society; 2008

18. Philip Lanzkowsky, Jeffrey M. Lipton, Jonathan D. Fish. Lanzkowsky's Manual of Pediatric Hematology and Oncology. 6th Edition. Academic Press.USA;2016.

19. Faiez N. Hattab. Patterns of physical growth and dental development in Jordanian children and adolescents with thalassaemia major. Journal of Oral Science.2013;55(1):71-77. doi:10.2334/ josnusd.55.71

20. Hashemi A MD, Ghilian R MD, Golestan M MD, Akhavan Ghalibaf M MD, Zare Z MD, Dehghani MA Msc. The Study of Growth in Thalassemia Patients and its Correlation with Serum Ferritin Level. Iranian Journal of Pediatric Hematology Oncology.2011;1(4).147-151

21. Mona Ramadan Nasr, Nermin Ali Ebrahim, Omnia Salahedin. Growth pattern in children with beta-thalassaemia major and its relation with serum ferritin, IGF1 and IGFBP3. J Clin Exp Invest. 2012;3(2):157-163. doi:10.5799/ahinjs.01.2012.02.0135 
Growth Pattern Among Yemeni Children Suffering from B Thalassemia Major in Relation to Serum Ferritin the Yemeni Society for Thalassemia and Genetic Blood Disorder - Sana'a Yemen

22. Vasundhara Kumari, SK Upadhyay, Vineeta Gupta, K Satya Piplani , BD Bhatia. Growth retardation and nutration in children with thalassaemia major. Indian J Prev Soc Med.2012;43(2):149-152.

23. Anita Saxena. Growth Retardation in Thalassaemia Major Patients. International Journal of Human Genetics.2003;3(4):237-246. doi:10.1080/09723757.2003.11885858

24. Olivieri NF, Nathan DG, MacMillan JH, Wayne AS, Liu PP, McGee A, et al. Survival in medically treated patients with homozygous betathalassemia. N Engl J Med. 1994;331(9):574-578.
Copyright:

(c) 2019 Abdullah A. K. Al-Tayar, et al. 